\title{
The patterns and prevalence of monosyllabic three-letter-word spelling errors made by South African English First Additional Language learners
}

\begin{tabular}{|c|c|}
\hline \multicolumn{2}{|c|}{$\begin{array}{l}\text { Authors: } \\
\text { Brahm Fleisch }{ }^{1} \\
\text { Kamala Pather }^{1} \\
\text { Geeta Motilal }^{1}\end{array}$} \\
\hline \multicolumn{2}{|c|}{$\begin{array}{l}\text { Affiliations: } \\
{ }^{1} \text { School of Education, } \\
\text { University of the } \\
\text { Witwatersrand, South Africa }\end{array}$} \\
\hline \multicolumn{2}{|c|}{$\begin{array}{l}\text { Corresponding author: } \\
\text { Brahm Fleisch, } \\
\text { brahm.fleisch@wits.ac.za }\end{array}$} \\
\hline \multicolumn{2}{|c|}{$\begin{array}{l}\text { Dates: } \\
\text { Received: } 17 \text { July } 2016 \\
\text { Accepted: } 16 \text { Feb. } 2017 \\
\text { Published: } 26 \text { July } 2017\end{array}$} \\
\hline \multicolumn{2}{|c|}{$\begin{array}{l}\text { How to cite this article: } \\
\text { Fleisch, B., Pather, K. \& } \\
\text { Motilal, G., 2017, 'The } \\
\text { patterns and prevalence of } \\
\text { monosyllabic three-letter- } \\
\text { word spelling errors made by } \\
\text { South African English First } \\
\text { Additional Language learners', } \\
\text { South African Journal of } \\
\text { Childhood Education 7(1), } \\
\text { a481. https://doi.org/ } \\
\text { 10.4102/sajce.v7i1.481 }\end{array}$} \\
\hline \multicolumn{2}{|c|}{$\begin{array}{l}\text { Copyright: } \\
\text { (C) 2017. The Authors. } \\
\text { Licensee: AOSIS. This } \\
\text { is licensed under the } \\
\text { Creative Commons } \\
\text { Attribution License. }\end{array}$} \\
\hline \multicolumn{2}{|l|}{ Read online: } \\
\hline 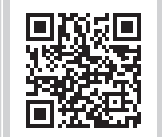 & $\begin{array}{l}\text { Scan this QR } \\
\text { code with your } \\
\text { smart phone or } \\
\text { mobile device } \\
\text { to read online. }\end{array}$ \\
\hline
\end{tabular}

There is growing evidence of systematic underachievement of South African primary school learners in reading in English as the first additional language. There is a small but growing literature that provides insights, that is, causes, patterns and prevalence, into this phenomenon. Through a secondary analysis of a spelling component of a literacy test that was administered as an end-line assessment for a randomised control trial, this article provides new evidence for and insight into the patterns and prevalence of English language spelling errors made by Grade 4 second-language learners. The study specifically coded errors on four monosyllabic three-letter words for 2500 Grade 4 learners tested individually at the end of the second term in 2014. Three distinct linguistic error patterns were identified. The most frequent error patterns involved the incorrect use of the vowel grapheme, for example bed was spelled 'bad'. The second pattern related to common errors associated with the transfer of linguistic, orthographic patterns from the first language (isiZulu). The final pattern suggests that between $6 \%$ and $8 \%$ of learners were struggling to make the basic phoneme-grapheme connection. This pattern, however, would need to be confirmed with oral interviews. The implications of these error patterns are discussed.

\section{Introduction}

The crisis in primary education in South Africa, as in many systems in the Global South, is now well documented (Fleisch 2008; Spaull 2015). The crisis has two major manifestations. The first is the bimodal distribution of achievement, that is, the substantial gap between relatively wellperforming learners of primarily middle-class schools and poorly performing learners attending schools in poor, rural and working-class communities. The second and related component of the crisis is the relatively low performance of the system as a whole, as benchmarked against comparable international and neighbouring countries (Fleisch 2008; Spaull 2015). The challenge in South Africa is how to concurrently address these two problems, that is, narrowing the gap and raising the overall performance of literacy learning. The earliest set of studies conducted since 1994 that have explored the dual challenge of high inequality and low performance have focused on the legacy of apartheid, particularly funding inequality (see, e.g., Fiske \& Ladd 2004). This research has often been complemented with sociological explanations that have focused on family background as a key determinant of unequal achievement. A second generation of scholars began to recognise that schools as institutions play a critical role in redressing inequality. These studies have focused on school and classroom factors that explain the dual problem of inequality and underachievement. Possibly, the most sophisticated of these studies was the National School Effectiveness Study, which not only provided longitudinal data on inter-year learning gains but also, more importantly, provided insights into within-school factors (Taylor, Van der Berg \& Mabogoane 2013). These studies have tended to focus on management problems, such as incomplete curriculum coverage and poor management and utilisation of resources. The latest wave of studies on educational inequality has gone deeper, to explore instructional issues within the relationship between learners, teachers and resources, so as to unpack underachievement. Draper and Spaull (2015), for example, have used government achievement data to show that the underachievement in literacy is strongly correlated with poor achievement in one particular precondition for comprehension, namely oral reading fluency.

This article contributes to this emerging body of research. We explore a relatively obscure and largely neglected interacting variable in second language (L2) reading, namely the variable 
of spelling. Drawing on a secondary analysis of prevalence and patterns of misspellings on an end-line subtest conducted as part of a randomised control trial (RCT), we found a number of common-type errors. The most prevalent error type was associated with the misspellings of the vowels in monosyllabic words. We also found high prevalence of errors associated with L1 language interference and learner errors that could best be characterised as pre-grapho-phonemic. Although explanation of the cause of the misspellings is beyond the scope of this study, we hypothesise that they may be an outcome of very limited and incomplete phonemic teaching, problems of dialect, a problem in the testing process or some combination of all of the above. The consequence of this is lack of access among learners to bottom-up strategies to encode and decode words.

\section{This study was animated by three questions:}

1. What are the patterns of spelling errors made by earlygrade learners learning English as a first additional language?

2. What are the prevalence rates of the various patterns?

3. What are the implications of the patterns and prevalence for understanding L2 reading underachievement?

The article is structured into four sections. The first section explores the literature on spelling errors and, to a lesser extent, the relationship between spelling error patterns and reading. The main concern is on the review studies that provide typologies of early-grade English spelling errors. The literature review also explores the limited conceptual and empirical work on common English spelling errors made specifically by African language-speaking learners in South Africa. The second section describes the research design of the original RCT study, exploring the rationale for the sampling frame utilised, the instruments used, the administration of the test and the capturing of the original data set. It also describes the secondary data analysis, the development of the coding scheme, the coding processes, the interrater reliability checks and the capturing processes. The findings section presents both broad descriptive statistics and more nuanced explorations of specific patterns and prevalence rates. In the concluding section, we point to the policy and research implications of the findings.

\section{Literature review}

Although research on spelling errors in English has been undertaken for more than 70 years (see, e.g., Wolff 1952), systematic investigation of this phenomenon has only really gathered momentum since the 1970s. The seminal paper by Read (1971) on 'invented' spelling is a marker for the beginning of what has become a well-established area of study. Over the past four decades, three distinct but interrelated questions have animated research and theory building on misspellings, or spelling errors. The first question relates to the developmental stages that learners go through, and how spelling errors change as learners progress through the various stages. The second question relates to the linguistic categories, or typologies, of spelling errors.
The final question engages the relationship between correct and incorrect spelling and learning to read. Each of these questions informs the current study.

Read's (1971) account of children's 'misspellings' (as opposed to canonical or correct spelling) explained the phonetic logic underlying children's spelling strategies: certain letters were often substituted or omitted, names of alphabetic letters were matched to the perceived speech sounds and children's knowledge developed systematically over a period of time as their exposure and understanding of written language increased. Subsequent research (Gentry 1982; Henderson \& Templeton 1986) examined children's developmental spelling changes in Grades 1 and 2. Gentry's (1982) research showed that learners progress through five distinct 'levels' of spelling. Gentry's stage theory posits that young learners begin at what Gentry refers to as a 'pre-communicative stage'. This stage has a number of characteristics, for example the learner has some knowledge of the alphabet, in the form of production of letter forms, but does not have an understanding of lettersound relationship. In the second stage, the learner moves to the 'semi-phonetic stage', in which they begin to conceptualise letter-sound relationships. In the third stage, the 'phonic stage', the child uses phonics to completely map letter-sound correspondence. In the later stages (the transitional and correct stages), the learner begins to incorporate English orthographic and morphological knowledge to achieve correct spelling. Henderson and Templeton (1986) follow more or less the same logic as Gentry's stage theory, but they go on to argue that the stage theory allows the teacher to determine the particular word features that the learner needs to study to advance in spelling competence. Schlagal's (1989) examination of children's error types as they transition from sound-letter and sound-pattern associations in the early grades to 'more complex levels of pattern and meaning in the upper grades' strengthened and advanced the argument that spelling progresses developmentally.

Consensus has emerged in the field that young learners make use of different types of knowledge to facilitate the process of spelling. Most scholars agree that phonological knowledge is essential at the earlier stages of learning to spell, but that orthographic and morphological knowledge is equally important as learners become competent at the more advanced levels. Phonological understanding involves knowledge of letter names and sounds, the ability to correctly segment words into phonemes and skill at linking phonemes to corresponding graphemes. Bourassa and Treiman (2009) $)^{1,2}$ summarise the new research that shows the nuances and complexities of phonological knowledge for spelling. Such complexities are, for example, learners' difficulties

1.Canonical or correct spelling is defined as the child's developing ability to choose one grapheme over another. This is the secondary level of spelling development (Holmes \& Babauta 2005, as cited in Ravid 2012). Furthermore, for the purposes of this article, the term 'misspelling' is defined as a child's initial reliance on the alphabetic principle that has a more or less consistent mapping between letters and alphabetic principle that has a more or less consistent mapping between letters and sounds. This is in contrast to 'orthographic or morphologically' correct spelling that 'designates a complex architecture relating phonology, morpho-syntax and lexicon
with orthography' (Ravid 2012:23).

2.We have adopted the convention used in Treiman (1991a), where the correct version of the word is written in italics, and the incorrect version is enclosed in quotation marks. 
with two-consonant syllable-initial clusters (Treiman 1991b). Although phonological knowledge is essential, in an opaque and deep orthography such as English, this is not sufficient for competent spellings. In other words, English is a 'morphologically complex writing system' (Rayner et al. 2012:283). The morphological complexity of English as a writing system results in multiple many-to-one mappings of graphemes to phonemes such as thud, rain and pick and phonemes to graphemes as in/e/in bed, began and like. The orthographic depth and consistency of isiZulu differ markedly from those of English in that isiZulu is a transparent and consistent orthography. This means that there is a direct one-to-one mapping between graphemes and phonemes and phonemes and graphemes, respectively. To this end, the pronunciation of words can be predicted through the spelling of words (Land 2015). Learners need to make use of orthographic knowledge, that is, knowledge of the written language, to master English spelling. Again, Bourassa and Treiman (2009) observe that in an environment saturated with print, even young learners bring orthographic knowledge, that is, their familiarity with printed word patterns, to the task of spelling. Children are able to do so only insofar as they receive increased exposure to new words, through deliberate teaching of these orthographic cues or self-teaching (Jorm \& Share 1983; Share 1995, as cited in Rayner et al. 2012:282). Finally, particularly as learners encounter more complex words, and their vocabulary grows, morphological knowledge becomes an increasingly important resource in spelling. The example that is often cited is the spelling of health, where knowledge of the related word heal can provide learners with key clues to the correct spelling of the word.

Nunes and Bryant (2009) argue that oral language is represented by written language in two ways, namely (1) the notational view in which written language encodes, records, transports and reproduces oral language in a systematic way. The notational view in English orthography is commonly recognised by the letter-sound correspondences, which do not have a consistent or transparent mapping - as discussed before. To this end, the term grapheme-phoneme correspondence is used rather than letter-sound correspondence to describe the morphological complexity of the alphabetic code that is used in the English language. (2) The second is the connection between oral and written language, which operates on an indirect level through the level of meaning encapsulated in syntax and morphology. Ravid (2012) argues that within the 'typological view of spelling development', very young children are quite sensitive to the 'typological imperatives' within their language. Simply put, children's linguistic learning is determined by the form-function patterns of their language. This argument is in line with Nunes and Bryant's (2009) second view of the connection between oral and written language. To this end, from the two aforementioned perspectives, that is, Nunes and Bryant's (2009) second view of the connection between oral and written language and Ravid's (2012) 'typological view of spelling development', there are three necessary knowledge domains for the acquisition of spelling in an alphabetic orthography. These knowledge domains are as follows: (1) how phonological segments map onto graphemes, (2) the specific properties of an orthographic system and (3) the nature of the grammatical, that is, morphological and syntactic segments represented by it (Ravid 2012:27). Furthermore, there is wide acknowledgement that spelling development is not strictly linear, as suggested in stage theories. It is also evident, however, that not all spelling knowledge is used simultaneously. As learners' vocabularies increase, as a result of continual and concurrent accumulation of language acquisition and literacy knowledge, so too does children's knowledge of orthographical properties as well as phonological and grammatical knowledge increase.

The literature also provides new insights into the common orthographic base upon which the encoding of words occurs through spelling and the decoding of words happens during reading pivot (Templeton \& Morris 2000). To this end, documented evidence in the literature reveals that there is a relationship between children's spelling development and their reading development. Henderson's hypothesis formulated in the late 1960s (Templeton \& Morris 2000) revealed that children's spelling of words provides insight into their reading of words or their lexical representation of words (Henderson 1981, as cited in Templeton \& Morris 2000). Similarly, Perfetti (1993170) argued that 'spelling and reading use the same lexical representation. In fact, spelling is a good test of the quality of representation'. The developmental phases of orthographic knowledge that are salient orthographic features that learners engage in during encoding and decoding processes are preliterate, letter name or alphabetic, within-word pattern, syllable juncture and derivational constancy (Beers \& Henderson 1997; Schlagel 2007; Morris 1983, 1993, as cited in Templeton \& Morris 2000). Therefore, Templeton (1992b), as quoted in Templeton \& Morris 2000), explains that if the learner is unable to commit to memory the full conventional orthographic representation of a word, then the manner in which the reader chooses to spell that same word will demonstrate the type of orthographic knowledge that he or she is using to perceptually process the word. However, reading and spelling words, through surface manifestations, may appear to be asynchronous, that is, a reader can read but not necessarily spell conventional words. Yet, Ehri (1987) argues that during both processes, that is, encoding and decoding, an individuals' orthographic knowledge is applied. Although there is a reciprocal relationship between spelling and reading, Frith (1995) showed that the ability to spell is more complex than the ability to read, as it requires active word production rather than passive word recognition. The idea is that early writing assists the learner to develop a lexical frame for words during early reading processes. Ehri's (1998) research showed that in the first few years before schooling, children's receptive vocabulary (i.e. words that they understand) is larger than their expressive vocabulary (i.e. words that they use to communicate). The research on the relationship between reading and spelling shows that learners' spelling ability predicts their reading success from the early grades (Berninger et al. 2010; Mann 1993; Treiman 1998). Teaching learners 
about the rules and patterns in spelling words inevitably improves both spelling and reading knowledge.

Within this framework, there is a growing body of research that is undertaking empirical work to identify 'fine-grained' misspelling patterns that will be relevant to teachers (see Arndt \& Foorman 2010; Berninger et al. 2010; Treiman \& Bowman 2015). There is an increase in the number of studies exploring specialised areas such as English vowel soundletter relationships (Treiman, Stothard \& Snowling 2013) and different patterns of spelling errors for average learners, as well as for learners with special needs.

Save for debates around the impact of African American dialects on patterns of spelling errors, much of the research had focused on middle-class first-language English learners. However, with the substantial demographic shift in school systems in the United States and other anglophone countries, there is growing interest in the patterns of spelling and misspelling of English-language learners (Bahr et al. 2015). There is growing research literature that focuses on spelling associated with learners that transfer from the L1 to an L2 (see, e.g., Raynolds, Uhry \& Brunner 2013).

There are about five recent South African studies that have relevance to this analysis of spelling errors. De Sousa, Greenop and Fry's (2010) comparative study of monolingual English speakers and emergent bilingual isiZulu-English Grade 3 learners reveals the important role of phonological awareness (PA) for the latter. De Sousa's (2011) research provides important clues to how spoken-only isiZulu (L1) influences the English (L2) reading acquisition process.

Seeff-Gabriel's (2003) study found strong correlations between learners' spelling of (English second language) words containing first language (L1) and second language (L2) vowels and their auditory discrimination and phonological representation of these words. Mpiti, in her study, found that 'learners have difficulty in noticing the different qualities of vowels or when the word has two vowels' (Mpiti 2012:99-100). She attributes this to learners' inability to distinguish two vowel sounds, and as a result, she found that learners tend to drop one of the vowels and add a consonant at the end, for example, spelling road as 'rodd'. She suggests that learners spell words the way they 'hear' them; thus, in some cases, the vowel $u$ is pronounced as/a/, for example, fun was spelt as ' $\mathrm{fan}^{\prime}$. $^{3}$ She associates these errors with phonemes that sound the same or similar in the home language (Mpiti 2012).

Although these studies are an important starting point for an understanding of the patterns and prevalence of spelling errors, they are based on small-scale, unrepresentative samples. There is a lacuna in the field. Knowledge needs to be built on large and random samples taken from English

\footnotetext{
3.Note that there is a word in isixhosa that sounds very similar to the English word fun. It is the word ifani, which has been borrowed from the Afrikaans word van fun. It is the word ifani, which has been borrowed from the Afrikaans word van,
which means 'surname'. It is thus not surprising that isiXhosa speakers would spell which means 'surname'. It is thu
the English word fun as 'fan'.
}

First Additional Language learners and their spelling artefacts. Such studies will provide insights into patterns of spelling errors, prevalence within the patterns and the relationship between spelling errors and underachievement in reading.

\section{Research design Participants}

The data for this study on spelling errors are drawn from learner literacy tests that were conducted as part of an RCT. The original study, the Reading Catch-up Study (RCUP), ${ }^{4}$ was a large-scale trial of a system-wide remedial programme designed as part of the Gauteng Primary Language and Mathematics Strategy to close the gap between learners' English language competence at the start of Grade 4 and the English language expectations as set out in the Curriculum and Assessment Policy Statement (CAPS) (see Fleisch et al. 2017). Joint Education Trust, an evaluation organisation with no links to the programme, was contracted to conduct pre- and post-tests in both treatment and control schools. The Pinetown district of KwaZulu-Natal province was the research site for the study. This particular study site was selected as it had a large number of Quintile 1-4 schools of different types (rural, urban, informal and formal).

Particular care was taken in designing the sampling frame and determining the sample size (see Fleisch et al. 2017). The intervention was aimed at a target population of functional but underperforming primary schools. Because the aim of the intervention was to remediate English reading achievement of underperforming primary school learners, the research team, which included university researchers and researchers from the Department of Basic Education (DBE), selected only schools where English was the Language of Teaching and Learning (LOLT) from Grade 4 onwards. Only schools that scored below 56\% in the 2012 and 2013 Grade 4 Annual National Assessments (ANAs) were selected. Schools were required to have no fewer than 15 and no more than 120 Grade 4 learners. (A few schools actually exceeded this number. $)^{5}$ The RCUP also excluded schools classified as Quintile 5 schools, which is the most affluent category of schools, according to the official school poverty classification system. Using these criteria, the RCUP randomly selected 100 schools that were qualified. ${ }^{6}$ These 100 schools were then randomly assigned: 40 schools to the treatment group and 60 schools to the control group.

\footnotetext{
4.In the original study, the terms reading and literacy were used interchangeably Given that the catch-up programme was designed to comply with the CAPS curriculum, most key aspects of literacy were covered including listening, speaking, reading and writing and sub-components of each.

5.This was justified on the grounds of cost. One of the two biggest cost drivers in this intervention were learner support materials (particularly the graded readers, the number of which is determined by learner numbers) and coaches' salaries.

6.Initially, we tried to select schools based on the initial sub-50\% ANA level and the 30-90 learners criterion. But in order to find 100 schools, we had to relax some of these criteria Read the full sampling report in the pre-a these criteria. Read the full sampling report in the pre-analysis plan to see exactly what we did. These sampling assumptions ultimately proved to be conservative particularly low intra-class correlation coefficient $(0.15)$ and a high correlation between baseline test scores and end-line test scores (0.8) meant that the study was actually powered to identify a minimum detectable effect size of 0.15 standard deviations, which turned out to be about $3.5 \%$ points in the reading test.
} 


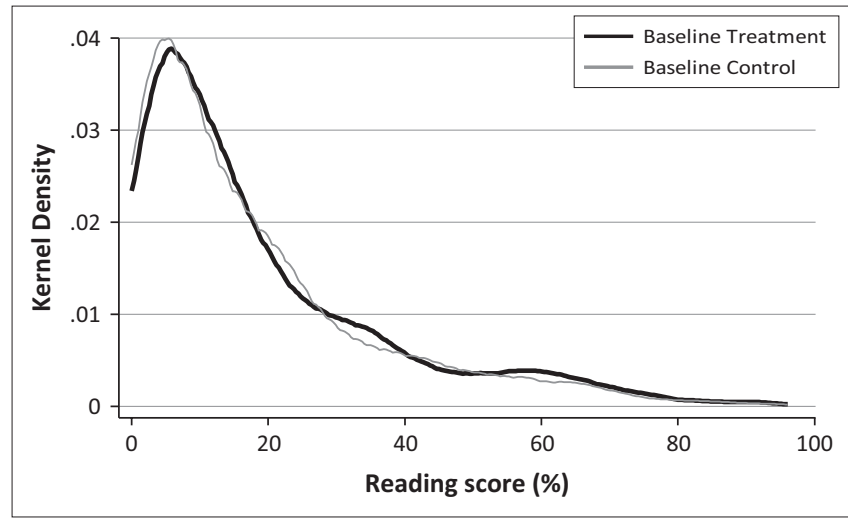

Source: Fleisch 2017

FIGURE 1: Kernel density of pre-test scores, percentage.

The RCUP study administered the pre-test to 2663 learners and the post-test to 2543 learners. The comparison of the means and distribution of the pre-test scores indicates that the treatment and control groups were almost identical, confirming that the randomisation was successful in generating two similar groups. The vast majority of learners in both groups scored in the low range on the test, confirming the findings in the existing literature on literacy achievement (see Figure 1).

\section{Test instruments}

The pre- and post-test instrument had four subtests, namely a spelling component, a language component, a vocabulary component and a comprehension component. Because of the concern about a 'floor effect' observed in the pre-test, the non-governmental organisation (NGO) responsible for the evaluation added six additional lowlevel items, two additional spelling words, namely mat and must, and four simple comprehension items. Information on the test functionality and item statistics are contained in Fleisch et al. 2017.

\section{Procedure, coding and capturing}

Both tests were administered one on one by experienced test administrators. The administrators said the word aloud, read a sentence containing the word and then repeated the word.? The learners then wrote the words on a blank numbered sheet. In the first round of coding for the original study, the field workers and supervisors coded the spelling subtest using a binary set of codes - correct and incorrect. Individual test marks were then captured on a spreadsheet for each item. Given the low aggregate scores on the spelling subtest (the 'floor effect'), the research team decided to initiate a secondary coding specifically to explore the error patterns and prevalence. The spelling error analysis, it was assumed, might provide new insights into the specific learning challenges that Grade 4 learners experience with knowledge of English phonology and orthography.

7.Information on whether the administrators were isizulu $\mathrm{HL}$ speakers and used local dialects was not collected. Similarly, no systematic information an teachers procts was not collected. Similarly, no systematic information an teachers pronunciation was collected as it was not central to the original intention of the RC study. That said, the absence of this information obviously limits the conclusions that can be drawn from the study.
Given the similar level of aggregate performance in the treated group and the control group on both the pre-test and the post-test, it was decided to use the post-test, as it included two additional spelling word items. A team of third-year education students was selected and trained to do the coding. The data coding system was developed during three successive workshops. In the first workshop, the team test coded the data using Arndt and Foorman's (2010) framework. This proved problematic, as the coders identified multipletype errors for each incorrectly spelt word. At the second workshop, the coders did not use a pre-specified framework, but were instead required to write down all possible misspelt permutations and record the frequency of each misspelt version. This also proved to be unmanageable. In the third workshop, we restricted the coding to four monosyllabic three-letter words and developed a framework with different types of grapheme-phonemic errors.

\section{Interrater reliability}

A process was set up to test for interrater reliability. The spelling words were first coded by the student teachers, who were familiar with spelling theory and had been trained in the use of the data coding system. The second coder, who is one of the authors of the article, independently recoded $20 \%$ of the test scripts. The results of the interrater reliability check showed an $80.4 \%$ match between the first coder and the second coder. The procedures for testing interrater reliability follow those used in Arndt and Foorman (2010) and guidelines provided in Cohen, Manion and Morrison (2011).

\section{Results \\ Overall results}

The first task was to analyse the frequency of correctly/ incorrectly spelt words and benchmark these results against the South African national curriculum. The RCUP spelling subtest consisted of 22 words, ranging from simple monosyllabic words with short vowel sounds, for example, bed and mat, to more complex multisyllabic words with complex structures such as split digraphs Vowel-Consonant-e (VCe) and trigraphs, for example, light. As is evident from Figure 2, the frequency of correctly spelt words ranged from $68.5 \%$ (for the word play) to $7 \%$ (for the word crime). For the three-letter words with a simple consonant-vowel-consonant (CVC) structure, 6 out of 10 learners made errors with the word bed, 7 out of 10 learners misspelt fun, 8 out of 10 learners misspelt the word mat and only 1 learner out of 10 could correctly spell the word rid.

The Curriculum and Assessment Policy Statements English First Additional Language document (DBE 2015:45) requires that by the first term of Grade 2, learners should be able to build up and break down three-letter words using the sounds learnt (e.g. p-e-n, p-en, t-e-n, t-en). By the second term, Grade 2 learners are expected to build up and break down simple words beginning with a single consonant into onsets and rimes (e.g. f-at, p-in, r-ed), and into individual sounds (e.g. f-a-t, p-i-n, r-e-d) (DBE 2015:50). In other words, by the 


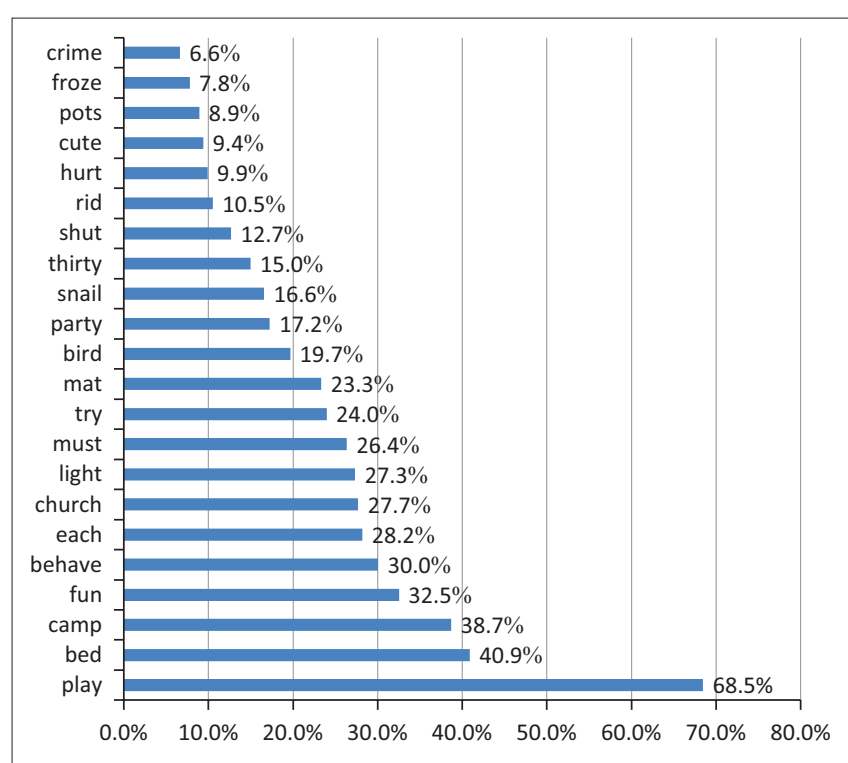

FIGURE 2: Scores for post-test: percentage of learners that spelt the word correctly.

second term of Grade 2, the South African national curriculum assumes that learners would be able to distinguish aurally between long and short vowel sounds (e.g. in the words not and note, and in the words hat and hate) (DBE 2015:50). The evidence from the spelling subtest reveals that over $60 \%$ of Grade 4 learners at the end of the second term in the Pinetown sample could not spell 'CAPS Grade 2' words. Although reading (decoding/passive word recognition) is cognitively less demanding than spelling (encoding/ active word production Nunes \& Bryant 2009; Templeton \& Morris 2000), the curriculum expectations require learners to be able to do both. Even after a 10 week daily reading/ (literacy) intervention, the overwhelming majority of learners remained 2 years behind in their spelling ability.

Notwithstanding the main finding in Figure 2, the pattern in the frequencies of incorrect word spellings contains striking anomalies. The most frequently correctly spelt word, namely play (68.5\% correct responses), contains two complex phonological and orthographic structures, namely the less common consonant blend $p l$ and the vowel blend ay. We can speculate that it is unlikely that these more complex linguistic structures had been systematically taught and learnt in classrooms if the early and developmentally more elementary phonic structures, such as the rime/at/in the words mat, cat, fat and hat, have not been introduced. ${ }^{8}$ Two rather complex words, namely behave and church, also have higher frequencies of correct spelling. Although more research is needed, this suggests that a substantial proportion of Pinetown learners may have learnt the word from readers, in mathematics lessons or learnt using incidental learning strategies to acquire knowledge of the spelling of some words in their lived environment. They are likely to use whole-word/sight-word and long-term memory, rather than phonotactic or morphotactic strategies (Bahr 2015).

8.One of the reviewers correctly observed that teachers could have taught the phonic structures out of sequence or teacher might have spend a lot of time drilling the lay/in maths lessons where kids learn the days of the week which all contain the /ay/sound. Further, play is a very frequently used word in beginner readers. Learners are likely to have seen it many times before. Also in teaching writing sentences teachers often teach the verbs like play, jump, run, sit first and they often drill teachers often teach the verbs like
learners on spelling these words.
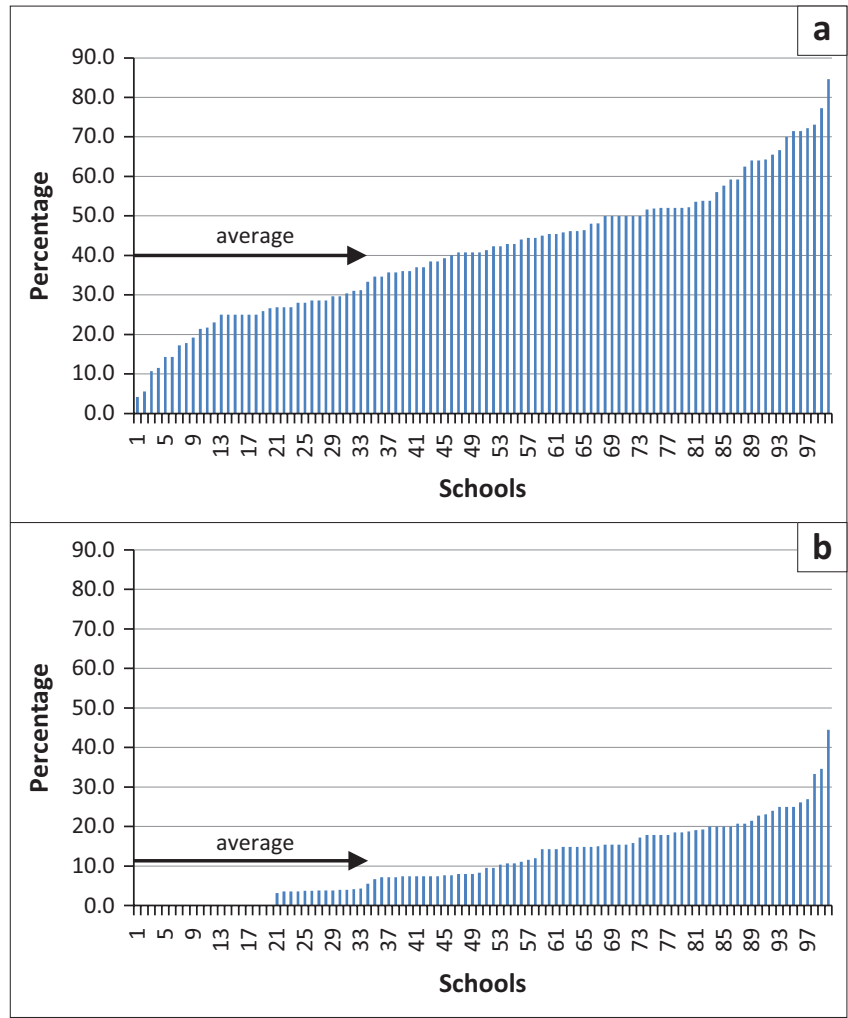

FIGURE 3: School correct spelling (a. bed, b. bid) averages.

Although the aggregate pattern of the RCUP sample is revealing, it is important to recognise that the schools were far from homogeneous. Figure 3 illustrates the betweenschool variability. The central tendency for the entire sample population masks the between-school variation.

Although we know that roughly $40 \%$ of Grade 4 learners in the Pinetown district did correctly spell bed, were good spellers disproportionately enrolled in certain schools? An analysis of the distribution showed a very wide range of school spelling aggregate performance with an aggregate school score below $30 \%$, with a third scoring above $50 \%$, and 10 schools with an aggregate spelling score at or above $70 \%$. In other words, good spelling performance varied considerably between schools.

\section{Linguistic characteristics of errors}

The core research questions that animated this study related to the patterns and prevalence of the spelling errors made by Grade 4 learners. The initial analyses provided important insights about the level of spelling performance relative to curriculum expectations and clues to possible incidental whole-word learning. The prevalence of correct and incorrect spelling provides a rough but useful indicator of the one key element of First Additional Language reading and literacy of South African learners at a critical transitional stage in their early years of schooling. An analysis of the specific spelling errors provides in-depth understanding of the dynamics of learning to decode and encode. Using the data coding system, we report on the pattern and prevalence of the spelling errors by error category and linguistic characteristic for the four 
TABLE 1: Aggregates from the error categories $(N=2536-2540)$.

\begin{tabular}{|c|c|c|c|c|c|c|c|c|c|c|c|}
\hline Number & Categories & bed & Bed $(\%)$ & fun & Fun $(\%)$ & rid & $\operatorname{Rid}(\%)$ & mat & Mat (\%) & Total & Tot $(\%)$ \\
\hline 99 & No answer/blank & 45 & 1.8 & 30 & 1.2 & 79 & 3.1 & 36 & 1.4 & 289 & 2.8 \\
\hline 0 & Word correct & 1037 & 40.9 & 828 & 32.6 & 283 & 11.1 & 626 & 24.7 & 2774 & 27.3 \\
\hline 1 & Alphabetic & 182 & 7.2 & 145 & 5.7 & 173 & 6.8 & 162 & 6.4 & 663 & 6.5 \\
\hline 2 & First phoneme correct & 127 & 5.0 & 484 & 19.1 & 263 & 10.4 & 549 & 21.6 & 1425 & 14.0 \\
\hline 3 & Last phoneme correct & 56 & 2.2 & 21 & 0.8 & 86 & 3.4 & 38 & 1.5 & 204 & 2.0 \\
\hline 4 & $\begin{array}{l}\text { Both initial phoneme and final } \\
\text { consonant correct }\end{array}$ & 961 & 37.9 & 910 & 35.9 & 1536 & 60.5 & 492 & 19.4 & 3903 & 38.5 \\
\hline 5 & $\begin{array}{l}\text { Initial phoneme incorrect, but 'e' added } \\
\text { to final correct phoneme }\end{array}$ & 8 & 0.3 & 1 & 0.0 & 5 & 0.2 & 1 & 0.0 & 20 & 0.2 \\
\hline 6 & $\mathrm{~d} / \mathrm{t}$ confusion & 1 & 0.0 & 0 & 0.0 & 0 & 0.0 & 29 & 1.1 & 36 & 0.4 \\
\hline 7 & $\begin{array}{l}\text { Incorrect use of the digraph 'th' at the end } \\
\text { of the word }\end{array}$ & 1 & 0.0 & 0 & 0.0 & 15 & 0.6 & 171 & 6.7 & 194 & 1.9 \\
\hline 8 & $\begin{array}{l}\text { Word correct, but incorrect letter added } \\
\text { before, in the middle, or at the end }\end{array}$ & 105 & 4.1 & 118 & 4.7 & 97 & 3.8 & 251 & 9.9 & 579 & 5.7 \\
\hline 9 & Reversal of the first and the last consonant & 11 & 0.4 & 0 & 0.0 & 3 & 0.1 & 0 & 0.0 & 23 & 0.2 \\
\hline 11 & Ends letter with an incorrect 'th' & 0 & 0.0 & 0 & 0.0 & 0 & 0.0 & 182 & 7.2 & 193 & 1.9 \\
\hline Total & & 2536 & 100 & 2537 & 100 & 2540 & 100 & 2537 & 100 & 10150 & 100 \\
\hline
\end{tabular}

TABLE 2: Spelling errors by linguistic characteristics.

\begin{tabular}{lcccc}
\hline Linguistic characteristic & Bed (\%) & Fun (\%) & Rid (\%) & Average (\%) \\
\hline Alphabetic & 13 & 9 & 8 & 10 \\
L1 interference & 16 & 36 & 17 & 9 \\
Semi-phonic (vowel error) & 66 & 54 & 71 & 33 \\
\hline
\end{tabular}

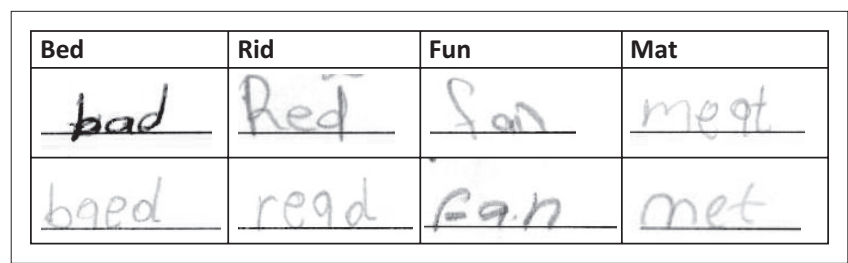

FIGURE 4: Incorrect middle vowel.

\begin{tabular}{|c|c|c|c|}
\hline Bed & Rid & Fun & Mat \\
\hline Bedi & $+1{ }^{\prime} i^{\prime}$ & Foln: & meth \\
\hline bhe di & $H_{i} \alpha_{i}^{*}$ & Eani' & \\
\hline
\end{tabular}

FIGURE 5: LI to L2 transfer (language interference).

\begin{tabular}{|l|l|l|l|}
\hline Bed & Rid & Fun & Mat \\
\hline fiminc & kimiblaib & buwms & imisuw \\
\hline msisin & $\frac{\text { nsiff }}{\text { ming }}$ & tats,i & menenl \\
\hline
\end{tabular}

FIGURE 6: Alphabetical.

monosyllabic three-letter words on the RCUP end-line test (see Table 1 and 2 and Figures 4-6 for examples).

During the first stage of the error analysis, we identified the need to go from a broad, or coarse-grained, analysis of the three broad linguistic error categories, phonemic, orthographic and morphological, to focus more explicitly on the developmentally simpler words, and a fine-grained analysis of the specific types of pre-grapho-phonemic and grapho-phonemic errors. Our focus on the earliest stages and most elementary skills allowed us to distinguish between learners with alphabetic skills and those with semi-graphophonemic skills and, more importantly, to identify the specific strengths and challenges learners have with specific aspects of phonemics. Our data coding system (see Table 1) would also allow us to identify the degree to which learners had difficulties with other common developmental challenges, such as letter reversals, for example the common reversal of ' $b$ ' and ' $d$ ', and phoneme confusions, such as the ' $\mathrm{d}$ ' and the ' $\mathrm{t}$ '.

Our results indicate that a relatively small proportion of learners did not attempt to provide any answer, and that the two types of errors, namely reversal of the first and the last consonant in the three-letter words, and the $\mathrm{d} / \mathrm{t}$ confusion, were rare. Across the four words, prevalence of the alphabetic, or pre grapho-phonemic, type of error was consistent, at around $6 \%-7 \%$. This may be an indication that around 7 in every 100 learners have not acquired a basic understanding of the relationship between phonemes and graphemes, a key stage in learning to read.

The most common error patterns, however, centred on errors with the middle vowel sounds and, to a lesser extent, patterns associated with the transfer of linguistic characteristics from the home language (isiZulu) to the first additional language (English). The most common error type for the monosyllabic words was correct identification of the first and the last consonant, but an error with the middle vowel sound.

9.A reviewer observed that reversals are often not challenges but naturally occurring stages in the development of visual invariance - it is common to find these still beyond the ages expected in schools catering to the poorest of the poor, because these kids had not had the quality or quantity of exposure to print before school as these kids had not had the
kids in the richest schools. 
TABLE 3: Correlations between subtest scores.

\begin{tabular}{lcccc}
\hline Sections & Spelling & Comprehension & Language & Writing \\
\hline Spelling & 1.00 & & & \\
Comprehension & 0.70 & 1.00 & & \\
Language & 0.68 & 0.66 & 1.00 & \\
Writing & 0.58 & 0.57 & 0.51 & 1.00 \\
\hline
\end{tabular}

Overall, almost $40 \%$ of all errors fell into this category. Within the three-letters words, there was some variation. The prevalence of this type of error for bed and fun was roughly of the same order, where the proportion of learners making this type of error was much higher for rid, and much lower for mat. It may be that the higher prevalence for rid is because this is a relatively uncommon word. If this is the case, the roughly $60 \%$ prevalence in which learners correctly identified the first and the last consonant and missed the vowel provides additional evidence that while many learners have mastered basic consonant phoneme-grapheme relationships, the key problem is with English vowel phonemes..$^{10}$ The error pattern with the word/mat/, however, and the relatively high prevalence of errors related to the last phoneme, incorrect use of the end digraph, additional letter added in the middle or at the end of the word and, particularly, the common incorrect ending with/th/rather than ' $t$ ' suggest transfer or L1 interference as the consonant ' $t$ ' occurs infrequently in isiZulu.

Table 3 provides useful insights into the size of the correlation between learners' performance on the spelling subtest and their performance on the comprehension subtest. There is a strong relationship; better spellers did better on the comprehension section. In general, the associations, however, do not provide insight into causation, that is, do better spelling skills lead to fluency, which in turn would lead to better comprehension, or do children who read well and understand what they have read become better spellers as a result of extended exposure to written text?

\section{Discussion}

How do these results contribute to the advancement of our understanding of the patterns and prevalence of English second language spelling errors? More broadly, how do the findings contribute to our understanding of reading in English as a second language for both the learners and the teacher? In this discussion, we identify four issues from the study that speak to the broader literature. The finding that over two-thirds of 2500 learners misspelt monosyllabic threeletter English words with a simple CVC structure (assumed by the curriculum to have been taught in the second term of Grade 2) confirms the substantial body of research about the reading and writing backlogs that most disadvantaged children carry into the middle years of schooling (see Draper \& Spaull 2015; Fleisch 2008; Howie, Venter \& Van Staden 2008; Pretorius 2014; Pretorius \& Currin 2010; Spaull 2015; Van der Berg 2015).

10.One of the reviewers pointed out that worldwide learners tend to learn the first and last consonant before learning the middle vowel in CVC words in English. and last consonant before learning the middle vowel in CVC words in English. However, they do not have a problem with the same vowels in VC words. The reviewer suggests that it is not the vowels that is the problem, but breaking the words into phonemes. It is simply easier to 'hear' the first and last sound than the middle one.
More importantly, the findings help provide clues to some of the underlying and early difficulties that many learners in the 'learning to read' (Snow, Griffin \& Burns 2005) phase experience. During the initial phase of learning to read, children should learn the alphabetic principle and lettersound relationships, they should encounter high-frequency words, and they should gradually begin to read basic texts with some level of automaticity, or fluency, and meaning (Arndt\&Foorman 2010). Weakness in reading comprehension, which has often been the primary interest of reading researchers, presupposes lack of mastery of the sequentially earlier literacy skills. This study points very directly to the weaknesses of one of the sequentially earliest literacy skills. Encoding, the task most closely associated with spelling, is cognitively more challenging than decoding, where learners can make use of other linguistic resources within the text (Nunes \& Bryant 2009; Templeton \& Morris 2000). It is clearly more difficult to write the correct spelling of the word/girl/ when a test administrator says the word than if a learner is asked to read the word/girl/as they see it printed on the page. In other words the process of encoding is a lot more difficult and cognitively demanding in comparison to the process of decoding. Notwithstanding this difference, the low levels of encoding in the spelling test point to the fact that learners fail the initial 'learning to read' hurdles. Learners are not effectively using their knowledge of the phonemegrapheme relationship to encode and, by logical extension, to decode. This is certainly not the first South African study that has showed this. Pretorius (2012), in her case study of middleschool reading in English and Northern Sotho in the Pretoria area, found that Grade 6 learners had very weak comprehension skills in both languages. She tracked these weaknesses back to serious weaknesses in decoding skills in both the first language and the second language.

The focus of the research questions of this study was not on the proportions of correct and incorrect spelling per se, although this has proven to be important, but rather on the specific patterns of misspellings, and the prevalence of these patterns in three-letter English words. Unlike Pretorius (2012:88), who found that the weakest learners found it 'difficult to distinguish and manipulate sounds at the beginning, middle and end of words', the recoding for error of patterns enabled a more fine-grained understanding of the gaps in phoneme-grapheme knowledge. Our evidence shows that the most prevalent error pattern was associated with incorrect identification of the middle vowel sound, for example bed is spelt 'bad', and rid is spelt 'read'. This weakness in this specific fine-grained phonemic skill has been highlighted in the existing literature. Seeff-Gabriel (2003) pointed to this, and noted the challenges that learners encounter moving from the five vowel sounds of isiZulu to the 22 vowel sounds of English. For more, see studies discussed in De Sousa, Greenop \& Fry. (2011).

One possible explanation for the high frequency of problems with the vowels and spelling may be related to secondlanguage learners' experience of how the vowel sounds feel 
in the mouth. Although consonants are articulated with the tongue, the teeth, the lips and the palate, vowels require subtle variations in the shape of the mouth ${ }^{11}$ and require vibrating the vocal cords. As learners in the early letter namealphabetic stage have difficulties segmenting vowels and consonants, particularly short vowel sounds, this may be a phonological segmentation problem.

The second relatively common error pattern we found is associated with what the literature has referred to as 'language interference', 'L1 to L2 transfer', or 'language interdependence' (Wagner 2011). This particular error pattern is most evident in the misspelling of the word mat as 'mathe' or/meth/. As Nguni languages generally do not have words that end with $a / t /$, learners are carrying over the isiZulu linguistic structure into the English spelling.

What is unique about our study is that we have estimates of the relative prevalence of these error types. Roughly $40 \%$ of the group of learners (including those that spelt the words correctly) made vowel errors but were able to correctly identify the first and the last consonant. The proportion of learners that made L1 to L2 transfer errors ranges from $8 \%$ to $15 \%$. An analysis of the error pattern also revealed that between $6 \%$ and $7 \%$ of learners appear to be at an alphabetical principle stage, that is, they are struggling to connect phonemes to corresponding graphemes. Although much more research is needed, our study suggests that this alphabetic group may require much intensive academic support.

Although it would be reasonable to dwell on the backlogs associated with the documented spelling errors, the evidence also points to some of the major strengths that the Pinetown learners bring to the reading process. The overwhelming majority of the Pinetown Grade 4 learners demonstrated familiarity with the evaluation task, with the spelling test in particular, and most demonstrated that they had a basic mastery of the phoneme-grapheme relationship. The relatively high level of success that the Pinetown learners had with words containing complex linguistic structures, as was the case with the word play, could be attributed to rote learning and drill. With some exceptions like the word day, monosyllabic words that combine the consonant blend/pl/ and the rime/ay/ would typically only be taught substantially later in the curriculum, in comparison with three-letter words with the same rime pattern, such as s-ay. What would account for this phenomenon? It is likely that learners have mastered the word play as a high-frequency sight word and have committed the sound and visual structure of the whole word to memory. This is also evident with other complex words, such as behave (30\% correct), church (28\% correct) and light ( $27 \%$ correct). These words have complex orthographic structures, such as the vowel-consonant-e in behave, and the unusual 'rch' and 'ght' trigraphs in church and light, respectively. If learners have not been exposed to systematic teaching of reading in English, the likely explanation for their

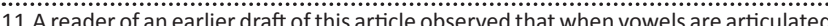
as opposed to consonants, the tongue is not brought into contact with any of the speech organs, but rather the airstream moves relatively unimpeded through the speech tract. relative success is incidental learning, that is, learning the sound and orthographic structure of sight words in their environment (Krashen 1989; Ramos \& Dario 2015).

\section{Conclusion}

The original intention of the RCUP was to evaluate the effectiveness of a large-scale remediation programme and to contribute to the body of knowledge on system-wide instructional reform. This was accomplished. During a review of the data sets used in the original evaluation, the research team, however, recognised that additional insights could be gained from a secondary analysis of the end-line test data set, particularly from recoding the spelling errors that the 2500 or so Grade 4 learners made on the first section of the test instrument. This article reports on the findings of the recoding and subsequent analysis and interpretation of the data.

The findings on the patterns and prevalence of spelling errors in a random sample of learners in 100 schools in the Pinetown district in KwaZulu-Natal both confirm and extend our knowledge of South African learners' reading and writing performance. In English language spelling, a competence that is integral to successful reading and writing, the study results show that over two-thirds of learners had not mastered the spelling of words that are benchmarked for Grade 2 learners. And although the learners brought some important literacy skills from reading and writing in their home language, may have been taught key word like play within certain routine daily routines and engaged in incidental learning from their environment, the unique pattern and prevalence of the spelling errors suggest that essential elements of a comprehensive English second language instructional programme may be missing in the first three years of schooling across the system.

Research is needed to confirm the findings of the patterns of spelling errors and to investigate the causal mechanisms associated with gaps in learners' orthographic knowledge. This will involve descriptive classroom practice studies of English First Additional Language teaching in the early grades. Concurrent with this, there is clearly a need to develop, pilot and trial interventions designed to improve teachers' teaching of English phonics and to help teachers build on an appropriate model of language skills transfer from the first language to the second language. We also need to know more about the distinct group of learners whose alphabetic pattern of errors suggests that they have a set of unique, albeit more serious, challenges.

\section{Acknowledgements}

Funding for this study has been provided by the National Research Foundation.

\section{Competing interest}

The authors declare that they have no financial or personal relationships that may have inappropriately influenced them in writing this article. 


\section{References}

Arndt, E.J. \& Foorman, B.R., 2010, 'Second graders as spellers: What types of errors are they making?', Assessment for Effective Intervention 36(1), 57-67. https://doi. org/10.1177/1534508410380135

Bahr, R., 2015, 'Spelling strategies and word formation processes', in R. Bahr \& E. Silliman (eds.), Routledge handbook of communication disorders, pp. 193-203, Routledge, London.

Bahr, R.H., Silliman, E.R., Danzak, R.L. \& Wilkinson, L.C., 2015, 'Bilingual spelling patterns in middle school: It is more than transfer', International Journal of Bilingual Education and Bilingualism 18(1), 73-91. https://doi.org/10.1080/1367 0050.2013 .878304

Beers, J.W. \& Henderson, E.H., 1997, 'A study of developing orthographic concepts among first grade children', Research in the Teaching of English 11, 133-148.

Berninger, V.W., Abbott, R.D., Nagy, W. \& Carlisle, J., 2010, 'Growth in phonological, orthographic, and morphological awareness in grades 1 to 6 ', Journal of Psycholinguistic Research 39(2), 141-163. https://doi.org/10.1007/s10936-009Psycholing

Bourassa, D. \& Treiman, R., 2009, 'Linguistic foundationzs of spelling development', in D. Wyse, R. Andrews \& J. Hoffman (eds.), Routledge international handbook of English, language and literacy teaching, pp. 182-192, Routledge, London, UK.

Cohen, L., Manion, L. \& Morrison, K., 2011, Surveys, longitudinal, cross-sectional and trend studies. Research methods in education, 7th edn., Routledge, Abingdon.

Department of Basic Education (DBE), 2015, Curriculum and assessment policy statement, viewed from http://www.education.gov.za/Portals/0/Documents/ Policies/NatProtAssess. pdf?ver=2015-02-03-154935-303. (14 January 2016)

De Sousa, D.S., 2011, 'Learning to read in English: Comparing monolingual English and bilingual Zulu-English Grade 3 learners', South African Journal of Childhood Education 1(1), 1-18. https://doi.org/10.4102/sajce.v1i1.70

De Sousa, D., Greenop, K. \& Fry, J., 2011, 'Cross-language transfer of spelling strategies in English and Afrikaans grade 3 children', International Journal of Bilingual Education and Bilingualism 14(1), 49-67. https://doi.org/10.1080/ 13670051003657959

De Sousa, D.S., Greenop, K. \& Fry, J., 2011, 'The effects of phonological awareness of Zulu-speaking children learning to spell in English: A study of cross-language transfer', British Journal of Educational Psychology 80(Pt 4), 517-533. https://doi. org/10.1348/000709910X496429

Draper, K. \& Spaull, N., 2015, 'Examining oral reading fluency among Grade 5 rural English Second Language (ESL) learners in South Africa? An analysis of NEEDU 2013', South African Journal of Childhood Education 5(2), 44-77. https://doi. org/10.4102/sajce.v5i2.390

Ehri, L.C., 1987, 'Learning to read and spell words', Journal of Reading Behavior 19, 5-31.

Ehri, L.C., 1998, 'Grapheme-phoneme knowledge is essential for learning to read words in English', in J.L. Metsala \& L.C. Ehri (Eds.), Word recognition in beginning literacy, pp. 3-40, Lawrence Erlbaum Associates, Mahwah, NJ.

Fiske, E.B. \& Ladd, H.F., 2004, Elusive equity: Education reform in post-apartheid South Africa, Brookings Institution Press, Washington, DC.

Fleisch, B., Taylor, S., Schöer, V. \& Mabogoane, T., 2017, 'Failing to catch up in reading in the middle years: The findings of the impact evaluation of the Reading Catch-Up Programme in South Africa', International Journal of Educational Developmen $53,36-47$.

Frith, U., 1995, 'Dyslexia: Can we have a shared theoretical framework?', Educational and Child Psychology 12, 6

Gentry, J.R., 1982, 'An analysis of developmental spelling in "GNYS AT WRK"', The Reading Teacher 36(2), 192-200.

Henderson, E.H. \& Templeton, S., 1986, 'A developmental perspective of formal spelling instruction through alphabet, pattern, and meaning', The Elementary spelling instruction through alphabet, pattern, and meaning',
School Journal 86(3), 305-316. https://doi.org/10.1086/461451

Howie, S., Venter, E. \& Van Staden, S., 2008, 'The effect of multilingual policies on performance and progression in reading literacy in South African primary schools' Educational Research and Evaluation 14(6), 551-560. https://doi.org/10.1080/ Educational Research
13803610802576775

Krashen, S., 1989, 'We acquire vocabulary and spelling by reading: Additional evidence for the input hypothesis', The Modern Language Journal 73(4), 440-464. https:// doi.org/10.1111/j.1540-4781.1989.tb05325.x

Land, S., 2015, 'Reading and the orthography of isizulu', South African Journal of African Languages 35(2), 163-175. https://doi.org/10.1080/02572117.2015.11 3000

Mann, V.A., 1993, 'Phoneme awareness and future reading ability', Journal of Learning Disabilities 26(4), 259-269. https://doi.org/10.1177/00222194930 2600406
Mpiti, T., 2012, 'Nature of spelling errors of grade three isiXhosa background learners in English first additional language', doctoral dissertation, University of Fort Hare.

Nunes, T. \& Bryant, P., 2009, Children's reading and spelling. Beyond the first steps, Wiley-Blackwell, Hong Kong.

Perfetti, C.A., 1992, 'The representation problem in reading acquisition', in P.B. Gough, L.C. Ehri \& R. Treiman (eds.), Reading acquisition, pp. 145-147, Lawrence Erlbaum Associates, Hillsdale, NJ.

Pretorius, E.J., 2012, 'Butterfly effects in reading? The relationship between decoding and comprehension in Grade 6 high poverty schools', Journal for Language Teaching/Tydskrif vir Taalonderrig 46(2), 74-95.

Pretorius, E.J., 2014, 'Supporting transition or playing catch-up in Grade 4? Implications for standards in education and training', Perspectives in Education 32(1), 51-76. https://doi.org/10.1016/j.ijedudev.2009.06.001

Pretorius, E.J. \& Currin, S., 2010, 'Do the rich get richer and the poor poorer?: The in a high poverty multilingual context', International Journal of Educational in a high poverty multilingur
Development $30(1), 67-76$.

Ramos, R. \& Dario, F., 2015, 'Incidental vocabulary learning in second language acquisition: A literature review', Profile Issues in Teachers Professional Development 17(1), 157-166. https://doi.org/10.15446/profile.v17n1.43957

Ravid, D.D., 2012, Spelling morphology: The psycholinguistics of Hebrew Spelling, Springer, New York. https://doi.org/10.1007/978-1-4419-0588-8

Rayner, K., Pollatsek, A., Ashby, J. \& Clifton, C., 2012, Psychology of reading, Taylor \& Francis Group, New York.

Raynolds, L.B., Uhry, J.K. \& Brunner, J., 2013, 'Vowel representations in the invented spellings of Spanish-English bilingual kindergartners', Reading and Writing 26(5), 647-664. https://doi.org/10.1007/s11145-012-9380-9

Read, C., 1971, 'Pre-school children's knowledge of English phonology', Harvard Educational Review 41(1), 1-34. https://doi.org/10.17763/haer.41.1.91367v0h 80051573

Schlagal, R.C., 1989, 'Constancy and change in spelling development', Reading Psychology: An International Quarterly 10(3), 207-232. https://doi.org/10.1080/ 0270271890100302

Schlagel, B., 2007, 'Best practices in spelling and handwriting', in S. Graham, C.A. MacArthur \& J. Fitzgerald (eds.), Best practices in writing instruction, pp. 179-201, Guilford Press, New York.

Seeff-Gabriel, B., 2003, 'Phonological processing: A platform for assisting secondlanguage learners with English spelling', Child Language Teaching and Therapy 19(3), 291-310. https://doi.org/10.1191/0265659003ct256oa

Snow, C.E., Griffin, P. \& Burns, M.S. (eds.), 2005, Knowledge to support the teaching of reading: Preparing teachers for a changing world, Jossey-Bass, San Francisco, CA.

Spaull, N., 2015, 'Schooling in South Africa: How low-quality education becomes a poverty trap', South African Child Gauge 12, 34-41.

Taylor, N., Van der Berg, S. \& Mabogoane, T. (eds.), 2013, Creating effective schools, Pearson, Cape Town, South Africa.

Templeton, S. \& Morris D., 2000, 'Spelling', in M.L. Kamil, P.B. Mosenthal, P.D. Pearson \& R. Barr (eds.), Handbook of reading research, vol. 3, pp. 525-543, Routledge, New York.

Treiman, R., 1991a, 'Children's spelling errors on syllable-initial consonant clusters', Journal of Educational Psychology 83(3), 346-360. https://doi.org/10.1037/0022 0663.83.3.346

Treiman, R., 1998, Why spelling? The benefits of incorporating spelling into beginning reading instruction', in J.L. Metsala \& L.C. Ehri (eds.), Word recognition in beginning literacy, pp. 289-313, Lawrence Erlbaum, Mahwah, NJ.

Treiman, R. \& Bowman, M., 2015, 'Spelling in African American children: The case of final consonant devoicing', Reading and Writing 28(7), 1013-1028. https://doi. org/10.1007/s11145-015-9559-y

Treiman, R. \& Kessler, B., 2013, 'Learning to use an alphabetic writing system', Language Learning and Development 9(4), 317-330. https://doi.org/10.1080/154 75441.2013.812016

Treiman, R., Stothard, S.E. \& Snowling, M.J., 2013, 'Instruction matters: Spelling of vowels by children in England and the US', Reading and Writing 26(3), 473-487. vowels by children in England and the US',
https://doi.org/10.1007/s11145-012-9377-4

Van der Berg, S., 2015, 'What the Annual National Assessments can tell us about learning deficits over the education system and the school career year', South African Journal of Childhood Education 5(2), 28-43. https://doi.org/10.4102/ sajce.v5i2.389

Wagner, D.A., 2011, Smaller, quicker, cheaper: Improving learning assessments for developing countries, UNESCO, Paris.

Wolff, M.R., 1952, 'A study of spelling errors with implications concerning pertinent teaching methods', The Elementary School Journal 52(8), 458-466. https://doi. org/10.1086/459380 